\title{
Nefopam does not influence onset and recovery profiles of rocuronium-induced neuromuscular block: a prospective, double-blinded, randomized, controlled study
}

Received December 26, 2017

Revised January 30, 2018

Accepted February 5, 2018

\section{Corresponding author}

Sang Hun Kim, M.D., Ph.D.

Department of Anesthesiology and

Pain Medicine, Chosun University

School of Medicine, 309 Pilmun-

daero, Dong-gu, Gwangju 61452,

Korea

Tel: 82-62-220-3223

Fax: 82-62-223-2333

E-mail: ksh3223@chosun.ac.kr ORCID

http://orcid.org/0000-0003-3869-9470

\author{
Keum Young So ${ }^{1,2}$, Hyun Mae Moon ${ }^{1}$, and Sang Hun Kim ${ }^{1,2}$ \\ Department of Anesthesiology and Pain Medicine, 'Chosun University Hospital, ${ }^{2}$ Chosun \\ University School of Medicine, Gwangju, Korea
}

Background: We investigated the hypothesis that pretreatment with nefopam $20 \mathrm{mg}$ would influence the onset and recovery profiles of rocuronium-induced neuromuscular block.

Methods: After Institutional Review Board approval, 134 patients, aged between 20-65 years, belonging to the American Society of Anesthesiologists physical status classification I or II, were randomly allocated to receive either $0.9 \%$ normal saline (control group) or nefopam $20 \mathrm{mg}$ (nefopam group), infused over one hour before induction of anesthesia. Anesthesia was induced with remifentanil and propofol, followed by endotracheal intubation with rocuronium $0.6 \mathrm{mg} / \mathrm{kg}$. We recorded the lag time, onset time, clinical duration, recovery index, recovery time, and total recovery time.

Results: We included 111 patients in the final analysis. The lag time, onset time, clinical duration, recovery index, recovery time, and total recovery time of the nefopam group ( $n=$ 57 ) were not significantly different compared with that of the control group $(n=54)$.

Conclusions: Pretreatment with nefopam $20 \mathrm{mg}$ one hour before induction of anesthesia does not have a significant influence on the onset and recovery profiles of rocuronium-induced neuromuscular block.

Key Words: Drug interactions, Nefopam, Neuromuscular monitoring, Neuromuscular nondepolarizing agents.

\section{INTRODUCTION}

Nefopam, a non-narcotic, nonsteroidal, centrally acting analgesic, is commonly used for the treatment of nociceptive pain and prevention of postoperative shivering and hiccups $[1,2]$. Most studies on nefopam have focused on its analgesic potency compared to that of opioids or non-steroidal antiinflammatory drugs. Nefopam was reported to be an effective alternative to opioids without significant changes in the Richmond Agitation Sedation Scale score, ventilatory frequency, and oxygen saturation [3]. Therefore, we can frequently encounter patients with many kinds of analgesic taken via infusions or single bolus injections, in the clinical setting requiring the control of preoperative pain such as disease-related pain and drug injection pain.

In general, neuromuscular blockers (NMBs) may interact with several drugs, including anticonvulsants, steroids, calcium channel blockers, antidepressants, antibiotics, and anti-arrhythmic drugs, resulting in potentiation of action or rapid recovery of blockade [4-8]. Hence, monitoring of neu-

This is an Open Access article distributed under the terms of the Creative Commons Attribution Non-Commercial License (http://creativecommons.org/licenses/by-nc/4.0) which permits unrestricted non-commercial use, distribution, and reproduction in any medium, provided the original work is properly cited. 
romuscular function and titration of dose are recommended in patients who are on these drugs. Nefopam is known to have a mechanism of action similar to that of serotonin, norepinephrine, and dopamine reuptake inhibitors in addition to inhibition of calcium influx similar to anticonvulsants. However, its mechanism of action has not been clearly established [1,2]. Furthermore, nefopam was initially developed as a muscle relaxant $[1,9,10]$. Therefore, it may be important to investigate its potential interaction with NMBs because of its presumed mechanism of action and initial development as a muscle relaxant.

To our knowledge, no study has investigated the effect of nefopam on rocuronium-induced neuromuscular block. We hypothesized that nefopam may influence neuromuscular block and conducted the present study to investigate whether nefopam pretreatment one hour before anesthesia would affect the onset and recovery profiles of rocuronium-induced neuromuscular block. The primary endpoint of the study was the onset time, and the secondary endpoint was the total recovery time.

\section{MATERIALS AND METHODS}

This prospective, randomized, controlled, double-blinded study was approved by the Institutional Review Board of the Chosun University Hospital (IRB no. 2016-02-002-001) on March 28, 2016 and registered with the Clinical Research Information Service (CRIS: https://cris.nih.go.kr) on July 5, 2016. Written informed consent was obtained from all participants and legal surrogates of participants who were minors.

We enrolled 134 patients aged 20-65 years, belonging to the American Society of Anesthesiologists physical status classification I or II, and scheduled to undergo elective surgery under general anesthesia. No significant differences in sex, age, height, weight, American Society of Anesthesiologists physical status classification, and body mass index (BMI) were found between groups (Table 1). We excluded patients who were on medications known to influence neuromuscular function, including furosemide, magnesium, cephalosporin, anticonvulsants, antidepressants, and analgesics. Patients with neuromuscular, cardiovascular, hepatic and renal diseases, glaucoma, allergy to nefopam, and risk of urinary retention were excluded. We also excluded breastfeeding women, and women who were pregnant or likely to get preg- nant during the study period. The study protocol adhered to the published guidelines for pharmacodynamic studies of NMBs [11].

Patients were randomly allocated to either the normal saline group (control group) or the nefopam group using a random number table (Fig. 1). In the control group ( $n=67), 102$ $\mathrm{ml}$ of $0.9 \%$ normal saline was infused one hour before induction of anesthesia at a rate of $100 \mathrm{ml} / \mathrm{h}$. In the nefopam group ( $\mathrm{n}=67$ ), nefopam $20 \mathrm{mg}(2 \mathrm{ml})$ in $100 \mathrm{ml}$ of $0.9 \%$ sodium chloride solution was infused one hour before induction of anesthesia at a rate of $100 \mathrm{ml} / \mathrm{h}$. Both patients and investigators were blinded to the study medication. A nurse who was not part of the investigating team loaded the drugs into indistinguishable, numbered syringes filled with the same volume (102 ml) of solution and randomized the medications using a random number table.

After premedication with intramuscular midazolam (0.05 $\mathrm{mg} / \mathrm{kg}$ ) 30 minutes before induction of anesthesia, patients were transferred to the operating room. Prior to the induction of anesthesia, standard patient monitoring devices including electrocardiogram, non-invasive blood pressure, end-tidal partial pressure of carbon dioxide $\left(\mathrm{ETCO}_{2}\right)$, and peripheral pulse oximetry were applied. Following this, the TOF-Watch ${ }^{\circledR}$ SX device (Organon Ireland Ltd., Ireland) was applied for assessment of neuromuscular function by acceleromyography of the adductor pollicis muscle by Train-of-Four (TOF) monitoring according to the manufacturer's recommendation. The stimulation cables were attached to the surface electrodes placed on the ulnar nerve, and the acceleration trans-

Table 1. Patient Characteristics

\begin{tabular}{lcc}
\hline \multicolumn{1}{c}{ Variable } & Control group $(\mathrm{n}=54)$ & Nefopam group $(\mathrm{n}=57)$ \\
\hline Sex (M/F) & $26 / 28$ & $18 / 39$ \\
ASA PS & $40 / 14$ & $48 / 9$ \\
$\quad$ classification $(\mathrm{I} / \mathrm{II})$ & & \\
Age $(\mathrm{yr})$ & $46.0(42.5-49.6)$ & $41.8(38.5-45.1)$ \\
Height $(\mathrm{cm})$ & $164.7(161.9-167.5)$ & $162.4(160.3-164.6)$ \\
Weight $(\mathrm{kg})$ & $66.5(63.4-69.6)$ & $63.5(60.6-66.4)$ \\
Body mass index & $24.4(23.7-25.2)$ & $23.9(23.1-24.7)$ \\
(kg/m $\left.{ }^{2}\right)$ & &
\end{tabular}

Values are expressed as number of patients or mean (95\% confidence interval). There are no significant differences between groups. $0.9 \%$ sodium chloride solution (control group) or nefopam $20 \mathrm{mg}$ (2 $\mathrm{ml}$ ) in $0.9 \%$ sodium chloride solution $100 \mathrm{ml}$ (nefopam group) was infused one hour before surgery at a rate of $100 \mathrm{ml} / \mathrm{h}$. ASA PS: American Society of Anesthesiologists physical status. 


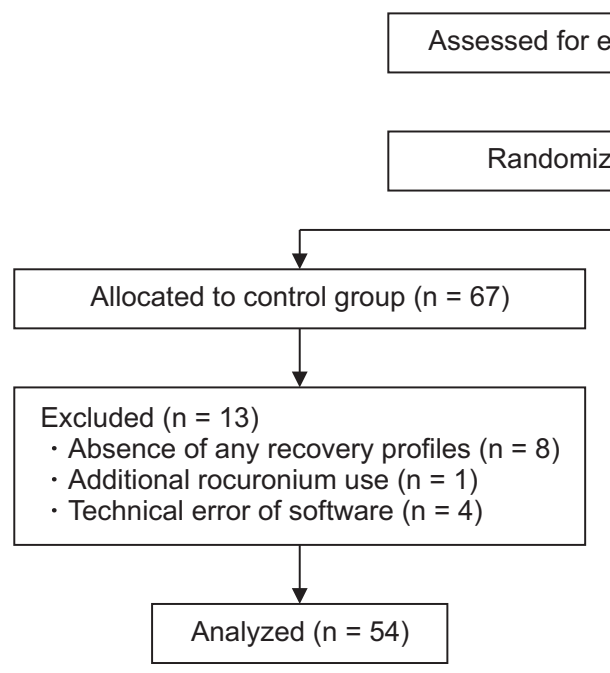

ducer was attached to the thumb. All fingers except thumb were kept immobile by means of adhesive tape and the arm was kept in the same position during the entire procedure.

Anesthesia was induced with remifentanil and propofol at target effect-site concentrations of $3.0 \mathrm{ng} / \mathrm{ml}$ and $3.0 \mu \mathrm{g} / \mathrm{ml}$ respectively, with a target-controlled infusion pump (Orchestra $^{\circledast}$, Fresenius Vial, France). One minute after equilibration of the target plasma and effect-site concentrations of propofol and remifentanil, the current required for supramaximal stimulus to achieve maximal response of the adductor pollicis muscle was obtained in each patient by using the automatic calibration mode. A separate investigator performed TOF stimulation to observe potentiation of the first twitch (T1) response of TOF; TOF ratios (TOFR) were assessed at $2 \mathrm{~Hz}$, every 15 seconds, with square wave pulses of $0.2 \mu$ s duration. Endotracheal intubation was performed after injection of rocuronium $0.6 \mathrm{mg} / \mathrm{kg}$ (ideal body weight) over 5-10 seconds following pretreatment with lidocaine $60 \mathrm{mg}$ intravenously. For maintenance of anesthesia, the target effect-site concentration of propofol and remifentanil were adjusted to maintain mean blood pressure within $20 \%$ of baseline levels and a bispectral index score in the range of 40 to 60 . Mechanical ventilation was carried out with $50 \%$ oxygen-air mixture and settings adjusted to maintain the $\mathrm{ETCO}_{2}$ between 35-45 mmHg. If patients showed increased muscular activity, or the surgeons required more muscle relaxation before obtaining a TOFR of 0.9 , we administered an additional dose of $0.3 \mathrm{mg} / \mathrm{kg}$ of rocuronium. These patients were excluded from the final analysis. Patients in whom surgery was completed within 1 hour and a TOFR of 0.9 was not obtained were also excluded from the final analysis. Neuromuscular block was reversed with sugammadex $2 \mathrm{mg} / \mathrm{kg}$, following which patients were transferred to the recovery room after confirming a TOFR of 0.9 .

We recorded the onset and recovery profiles as follows: 1) the duration in seconds from the start of rocuronium injection until a change was observed in the $\mathrm{Tl}$ response of TOF (lag time, LT), 2) the duration in seconds from the start of rocuronium injection until maximum or $95 \%$ depression of the $\mathrm{T} 1$ response (onset time, OT), 3) the duration in minutes between the start of rocuronium injection and $25 \%$ recovery of twitch height of the $\mathrm{T} 1$ response (clinical duration, $\mathrm{CD}$ ), 4) the duration in minutes between 25 and $75 \%$ recovery of twitch height of the $\mathrm{Tl}$ response (recovery index, RI), 5) the duration in minutes between the $25 \%$ recovery of twitch height recovery of the $\mathrm{Tl}$ response and recovery of neuromuscular block to a TOFR of 0.9 (recovery time, RT), 6) the duration between the start of rocuronium injection till recovery of neuromuscular block to a TOFR of 0.9 (total recovery time, TRT). The age, sex, American Society of Anesthesiologists physical status classification, height, weight, and BMI were also noted.

\section{Statistical analysis}

The primary endpoint was the onset time, and the secondary endpoint was the total recovery time. The sample size required was calculated using $t$-tests with $\mathrm{G}^{*}$ Power software (ver. 3.1.9.1, Heinrich-Heine-Universität Düsseldorf, Germany) at a level of statistical significance of $\alpha=0.05$ and $\beta=$ 0.2 using an expected effect size of 0.5 , which is the medium 
effect size (0.5) suggested by Cohen; this was due to lack of clinical evidence in literature to calculate effect size [12]. We required a total of 128 patients; 134 patients were enrolled, assuming a $5 \%$ dropout rate.

We used SPSS (Windows ver. 21.0, IBM Corp., USA) software for statistical analysis. All measured values are presented as mean (95\% confidence interval) or number of patients (n).

We excluded data of patients from whom we could not get any results of the onset and recovery profiles. The LT, OT, CD, RI, RT, TRT, age, height, weight, and BMI were analyzed using the student $t$-test after confirming normal distributions by the Levine's test. Sex and American Society of Anesthesiologists physical status classification were analyzed using the $\chi^{2}$ test. $\mathrm{P}$ values $<0.05$ were considered statistically significant.

\section{RESULTS}

We included 111 patients in the final analysis. Twentythree patients (13 in the control group, and 10 in the nefopam group) were excluded from the final analysis because of incomplete collection of recovery profiles (Fig. 1). No significant differences in sex, age, height, weight, American Society of Anesthesiologists physical status classification, and BMI were found between groups (Table 1).

There was no significant difference in LT between the nefopam group and the control group $(P=0.949$, Table 2$)$. The OT and CD were not significantly different between groups ( $\mathrm{P}=0.609$ and 0.447 respectively, Table 2 ). Similarly, the RI,

Table 2. Onset and Recovery Profiles of Rocuronium-induced Neuromuscular Block

\begin{tabular}{lccc}
\hline Profiles & Control group $(n=54)$ & Nefopam group $(n=57)$ & P value \\
\hline LT $(\mathrm{s})$ & $57.5(51.8-63.1)$ & $56.2(51.0-61.4)$ & 0.949 \\
OT $(\mathrm{s})$ & $121.4(108.1-134.6)$ & $116.9(106.3-127.4)$ & 0.609 \\
CD $($ min) & $36.0(31.8-40.2)$ & $36.7(33.6-39.9)$ & 0.447 \\
RI (min) & $15.1(12.7-17.5)$ & $14.4(12.5-16.3)$ & 0.737 \\
RT (min) & $27.1(24.4-29.8)$ & $29.1(26.2-32.0)$ & 0.444 \\
TRT (min) & $63.0(57.9-68.1)$ & $65.6(61.0-70.2)$ & 0.530 \\
\hline
\end{tabular}

Values are expressed as mean (95\% confidence interval). There are no significant differences on the onset and recovery profiles between groups. $0.9 \%$ sodium chloride solution (control group) or nefopam 20 $\mathrm{mg}(2 \mathrm{ml})$ in $0.9 \%$ sodium chloride solution $100 \mathrm{ml}$ (nefopam group) is infused one hour before surgery at a rate of $100 \mathrm{ml} / \mathrm{h}$. LT: lag time, OT: onset time, CD: clinical duration, Rl: recovery index, RT: recovery time, TRT: total recovery time.
RT, and TRT of the nefopam group were also not significantly different compared with that of the control group $(\mathrm{P}=0.737$, 0.444 , and 0.530 respectively, Table 2 ).

\section{DISCUSSION}

Our results show that pretreatment with nefopam $20 \mathrm{mg}$ does not affect the onset and recovery profiles of rocuroniuminduced neuromuscular block.

Nefopam produces analgesic effect by inhibitory mechanisms similar to serotonin reuptake inhibitors and anticonvulsants, which may affect NMBs-induced neuromuscular block $[1,13]$.

5-hydroxytryptamine $3\left(5-\mathrm{HT}_{3}\right)$ receptor antagonists have an inhibitory effect on nicotinic acetylcholine receptors and affect neuromuscular transmission, because of the structural similarities and common evolutionary origin of muscle nicotinic acetylcholine and $5-\mathrm{HT}_{3 \mathrm{~A}}$ receptors $[7,8]$. Therefore, serotonin reuptake inhibitors may interact with non-depolarizing NMBs. In an animal study, Patel et al. [7] showed that serotonin reuptake inhibitors significantly inhibited twitch responses by blocking neuromuscular transmission and increasing the potency of rocuronium-induced neuromuscular block. The interaction of $5-\mathrm{HT}_{3}$ receptor antagonists with non-depolarizing NMBs is related to antiemetic potency [14]. Nefopam may have possible drug interaction with NMBs because it inhibits the uptake of triple neurotransmitters (serotonin, dopamine, and norepinephrine) as order of binding potency [1]. However, there are no reports on drug interaction with nefopam, although it is bound minimally to the $5-\mathrm{HT}_{3}$ receptor [1]. This may explain the absence of drug interaction between nefopam and rocuronium that we observed in our study.

Acute or chronic anticonvulsant therapy significantly hastens recovery from, but does not affect the onset and duration of non-depolarizing NMBs $[5,15]$. Preoperative chronic administration of anticonvulsants significantly hastens recovery index of non-depolarizing NMBs, and a higher infusion rate is required to maintain $95 \%$ twitch depression $[6,16,17]$. Rapid recovery of non-depolarizing NMBs occurs due to enhanced clearance and reduced sensitivity to circulating concentrations following chronic anticonvulsant therapy $[16,18]$. However, acute administration of anticonvulsants may increase sensitivity to non-depolarizing NMBs as a result 
of direct pre- and post-junctional effects; anticonvulsants have only mild neuromuscular effects of their own $[17,19]$. In this study, nefopam, with a mechanism of action similar to anticonvulsants, did not affect onset and recovery profiles of rocuronium-induced neuromuscular block. A possible explanation for this finding may be induction of hepatic enzymes by anticonvulsants, which can increase the elimination of non-depolarizing NMBs. Nefopam is a non-enzyme inducing drug [20]; this may explain why a single dose may not hasten recovery index from neuromuscular block, or lead to more rapid recovery from non-depolarizing NMBs.

Cardiac output and blood pressure also influence onset and recovery profiles of non-depolarizing NMBs [13]. Ephedrine leads to a rapid onset of action of NMBs by increasing the cardiac output, while beta blockers with negative inotropic and chronotropic effects delay onset of action [13]. Nefopam also increases cardiac output, but this effect is offset by the tachycardia that it induces, hypotension, and decreased systemic vascular resistance [3]. This may also be one of the reasons that we could not demonstrate any interaction between nefopam and rocuronium.

Intravenous nefopam may cause adverse effects such as dry mouth, sedation, dizziness, sweating, tachycardia, nausea and vomiting, diplopia, and dysphoria [1,21-24]. Kim and Abdi [1] report that adverse drug reactions and the need for cessation of administration are rare if nefopam is given in single doses of $20 \mathrm{mg}$ slowly over 15-20 minutes or as a continuous infusion of $60-120 \mathrm{mg} / \mathrm{d}$. The manufacturer also recommends slow injection in order to prevent adverse reactions. Hence, we infused nefopam $20 \mathrm{mg}$ one hour before induction of anesthesia at $100 \mathrm{ml} / \mathrm{h}$; we did not observe significant adverse reactions during or after administration.

There are some limitations associated with the present study. First, we did not evaluate the effect of nefopam on onset and recovery profiles of rocuronium in patients receiving long-term nefopam treatment. Second, we cannot ignore that nefopam may influence the effect of NMBs depending on the time to maximal plasma concentration and elimination halflife time, which are 0.63 hour and close to 5 hours, respectively, after a single dose intravenous infusion of $20 \mathrm{mg}$ over 30 minutes [25]. Furthermore, the more rapid the rate of infusion of nefopam, the higher the peak plasma concentration and longer the elimination half-life time [26]. However, we recorded the characteristics of rocuronium-induced neuro- muscular block immediately after infusion of $20 \mathrm{mg}$ nefopam over 1 hour; we did not wait until the peak plasma concentration was attained. This may have reduced the likelihood of any effect on rocuronium-induced neuromuscular block. Considering these limitations, further studies are required to investigate whether nefopam has any interaction with NMBs. Finally, in our search of literature, we could not find any information on the interaction between NMBs and skeletal muscle relaxants, although nefopam exhibited a direct muscle relaxant action in the treatment of chronic hiccups [27].

In conclusion, nefopam $20 \mathrm{mg}$ infused slowly over one hour before induction of anesthesia does not interact with rocuronium. This is probably because it is minimally bound to the $5-\mathrm{HT}_{3}$ receptor and does not induce hepatic enzymes; hence it does not influence the elimination of non-depolarizing NMBs.

\section{ACKNOWLEDGMENTS}

This study was supported by research fund from Chosun University, 2017.

\section{REFERENCES}

1. Kim KH, Abdi S. Rediscovery of nefopam for the treatment of neuropathic pain. Korean J Pain 2014; 27: 103-11.

2. Gregori-Puigjané E, Setola V, Hert J, Crews BA, Irwin JJ, Lounkine $\mathrm{E}$, et al. Identifying mechanism-of-action targets for drugs and probes. Proc Natl Acad Sci U S A 2012; 109: 11178-83.

3. Chanques G, Sebbane M, Constantin JM, Ramillon N, Jung B, Cissé $\mathrm{M}$, et al. Analgesic efficacy and haemodynamic effects of nefopam in critically ill patients. Br J Anaesth 2011; 106: 336-43.

4. Spacek A, Neiger FX, Krenn CG, Hoerauf K, Kress HG. Rocuronium-induced neuromuscular block is affected by chronic carbamazepine therapy. Anesthesiology 1999; 90: 109-12.

5. Koenig HM, Hoffman WE. The effect of anticonvulsant therapy on two doses of rocuronium-induced neuromuscular blockade. J Neurosurg Anesthesiol 1999; 11: 86-9.

6. Kawamura G, Inoue R, Araki Y, Mori Y, Sato K, Yamada Y, et al. Effects of preoperatively administered carbamazepine and phenytoin on rocuronium-induced neuromuscular block under sevoflurane anesthesia: a retrospective clinical study. Masui 2014; 63: 877-80.

7. Patel JC, Barvaliya MJ, Patel TK, Tripathi CB. Neuromuscular blocking effect of fluoxetine and its interaction with rocuronium. Auton Autacoid Pharmacol 2013; 33: 17-24. 
8. Min KT, Wu CL, Yang J. Nondepolarizing neuromuscular blockers inhibit the serotonin-type $3 \mathrm{~A}$ receptor expressed in Xenopus oocytes. Anesth Analg 2000; 90: 476-81.

9. Tobin WE, Gold RH. Nefopam hydrochloride: a novel muscle relaxant. J Clin Pharmacol New Drugs 1972; 12: 230-8.

10. Bolt AG, Graham G, Wilson P. Stereoselective demethylation of the enantiomers of nefopam, an experimental antidepressant and skeletal muscle relaxant. Xenobiotica 1974; 4: 355-63.

11. Fuchs-Buder T, Claudius C, Skovgaard LT, Eriksson LI, Mirakhur RK, Viby-Mogensen J. Good clinical research practice in pharmacodynamic studies of neuromuscular blocking agents II: the Stockholm revision. Acta Anaesthesiol Scand 2007; 51: 789-808.

12. Cohen J. A power primer. Psychol Bull 1992; 112: 155-9.

13. Kim YB, Sung TY, Yang HS. Factors that affect the onset of action of non-depolarizing neuromuscular blocking agents. Korean J Anesthesiol 2017; 70: 500-10.

14. Paul M, Callahan R, Au J, Kindler CH, Yost CS. Antiemetics of the 5-hydroxytryptamine 3A antagonist class inhibit muscle nicotinic acetylcholine receptors. Anesth Analg 2005; 101: 715-21.

15. Koenig MH, Edwards LT. Cisatracurium-induced neuromuscular blockade in anticonvulsant treated neurosurgical patients. J Neurosurg Anesthesiol 2000; 12: 314-8.

16. Richard A, Girard F, Girard DC, Boudreault D, Chouinard P, Moumdjian R, et al. Cisatracurium-induced neuromuscular blockade is affected by chronic phenytoin or carbamazepine treatment in neurosurgical patients. Anesth Analg 2005; 100: 538-44.

17. Kim JU, Lee YK, Lee YM, Yang HO, Han SM, Yang HS. The effect of phenytoin on rocuronium-induced neuromuscular block in the rat phrenic nerve-hemidiaphragm preparation. J Neurosurg Anesthesiol 2005; 17: 149-52.

18. Wright PM, McCarthy G, Szenohradszky J, Sharma ML, Caldwell JE. Influence of chronic phenytoin administration on the pharmacokinetics and pharmacodynamics of vecuronium. Anesthe- siology 2004; 100: 626-33.

19. Soriano SG, Martyn JA. Antiepileptic-induced resistance to neuromuscular blockers: mechanisms and clinical significance. Clin Pharmacokinet 2004; 43: 71-81.

20. Bounds W, Guillebaud J. Observational series on women using the contraceptive Mirena concurrently with anti-epileptic and other enzyme-inducing drugs. J Fam Plann Reprod Health Care 2002; 28: 78-80.

21. Mimoz O, Incagnoli P, Josse C, Gillon MC, Kuhlman L, Mirand A, et al. Analgesic efficacy and safety of nefopam vs. propacetamol following hepatic resection. Anaesthesia 2001; 56: 520-5.

22. Kapfer B, Alfonsi P, Guignard B, Sessler DI, Chauvin M. Nefopam and ketamine comparably enhance postoperative analgesia. Anesth Analg 2005; 100: 169-74.

23. Tirault M, Derrode N, Clevenot D, Rolland D, Fletcher D, Debaene B. The effect of nefopam on morphine overconsumption induced by large-dose remifentanil during propofol anesthesia for major abdominal surgery. Anesth Analg 2006; 102: 110-7.

24. Yoo JY, Lim BG, Kim H, Kong MH, Lee IO, Kim NS. The analgesic effect of nefopam combined with low dose remifentanil in patients undergoing middle ear surgery under desflurane anesthesia: a randomized controlled trial. Korean J Anesthesiol 2015; 68: 43-9.

25. Aymard G, Warot D, Démolis P, Giudicelli JF, Lechat P, Le Guern ME, et al. Comparative pharmacokinetics and pharmacodynamics of intravenous and oral nefopam in healthy volunteers. Pharmacol Toxicol 2003; 92: 279-86.

26. Mather GG, Labroo R, Le Guern ME, Lepage F, Gillardin JM, Levy RH. Nefopam enantiomers: preclinical pharmacology/toxicology and pharmacokinetic characteristics in healthy subjects after intravenous administration. Chirality 2000; 12: 153-9.

27. Bilotta F, Pietropaoli P, Rosa G. Nefopam for refractory postoperative hiccups. Anesth Analg 2001; 93: 1358-60. 